\title{
Identifying Representative Crop Rotation PATterns And Grassland LOSS IN THE US WESTERN CORN BELT
}

Ritvik Sahajpal $^{* 1}$, Xuesong Zhang ${ }^{2,3}$, R. César Izaurralde ${ }^{1,3}$, Ilya Gelfand ${ }^{3,4}$, George C. Hurtt ${ }^{1,2}$

${ }^{1}$ Department of Geographical Sciences, University of Maryland, College Park, MD 20742

${ }^{2}$ Joint Global Change Research Institute, Pacific Northwest National Laboratory and University of Maryland, 5825 University Research Court Suite 3500, College Park, MD 20740

${ }^{3}$ Great Lakes Bioenergy Research Center, Michigan State University, East Lansing, MI 48824

${ }^{4}$ W.K. Kellogg Biological Station, Michigan State University, Hickory Corners, MI 49060

* Corresponding author: ritvik@umd.edu 
Abstract. Crop rotations (the practice of growing crops on the same land in sequential seasons) reside at the core of agronomic management as they can influence key ecosystem services such as crop yields, carbon and nutrient cycling, soil erosion, water quality, pest and disease control. Despite the availability of the Cropland Data Layer (CDL) which provides remotely sensed data on crop type in the US on an annual basis, crop rotation patterns remain poorly mapped due to the lack of tools that allow for consistent and efficient analysis of multi-year CDLs. This study presents the Representative Crop Rotations Using Edit Distance (RECRUIT) algorithm, implemented as a Python software package, to select representative crop rotations by combining and analyzing multi-year CDLs. Using CDLs from 2010 to 2012 for 5 states in the US Midwest, we demonstrate the performance and parameter sensitivity of RECRUIT in selecting representative crop rotations that preserve crop area and capture land-use changes. Selecting only 82 representative crop rotations accounted for over $90 \%$ of the spatio-temporal variability of the more than 13,000 rotations obtained from combining the multi-year CDLs. Furthermore, the accuracy of the crop rotation product compared favorably with total state-wide planted crop area available from agricultural census data. The RECRUIT derived crop rotation product was used to detect land-use conversion from grassland to crop cultivation in a wetland dominated part of the US Midwest. Monoculture corn and monoculture soybean cropping were found to comprise the dominant land-use on the newly cultivated lands. 
Keywords. Cropland data layer, Crop rotations, US Midwest, RECRUIT algorithm, Prairie Pothole Region

\section{Introduction}

\subsection{Background}

As the dominant land-use type on Earth, agro-ecosystems cover more than a third of ice-free land surface (Ramankutty et al., 2008). They have a profound impact on the environment which is manifested through global fluxes of greenhouse gases (McCarl and Schneider, 2001), soil carbon dynamics (Lal, 2004), increased surface temperature and drought conditions (Hertel et al., 2010), and provision of ecosystem services (Foley et al., 2011). Human management of these agroecosystems, based on economic realities and ecological conditions, can influence both the magnitude and the nature of impact on ecosystem services (Robertson at al., 2000).

A key management activity performed by farmers is the development of crop rotation plans based on economic opportunities and adapted to environmental conditions. Crop rotations have been practiced for thousands of years but crop rotations practiced today are much simpler than those practiced in the past (Bullock, 1992 and Plourde et al., 2013). Compared to a monoculture cropping system supplied with optimum nutrient levels, the practice of crop rotations usually leads to higher yields, which are mainly attributed to improved soil fertility and tilth (Hesterman et al., 1987 and Pierce and Rice, 1988), as well as enhanced pest, disease and weed control (Liebman and Dyck, 1993 and Tilman et al., 2002). When practiced together with a low-intensity tillage regime, crop rotations can potentially reduce the global warming potential of agroecosystems (West and Post, 2002). Conversely, the simplification of agro-ecosystems, through expansion of agricultural land supporting a single crop type is an important cause behind the 
decline in farmland biodiversity (Bianchi et al., 2006). Consequently, ecosystem services associated with diversified crop rotations, like nutrient recycling, addition of organic matter and microclimate regulation have also deteriorated. Beyond their ecological importance, these ecosystem services provide other tangible benefits. For instance, the suppression of pest populations in crops by natural enemies can reduce yield loss and the need for increased use of pesticides (Landis et al., 2008, Gardiner et al., 2009 and Meehan et al., 2011), although there is uncertainty about the linkage between landscape simplification and pesticide use (Larsen, 2013). With the advent of synthetic fertilizers and pesticides in the 1950s, use of crop rotations declined (Bullock, 1992). However, the increased intensification did not boost yields in comparison to a judicious crop rotation scheme (Mannering and Griffin, 1981). Amidst mounting concerns over the impacts of increased chemical inputs on surface and groundwater quality (Turner and Rabalais, 2003), there has been a renewed interest in crop rotations over the last couple of decades. A confluence of factors is expected to influence the crop rotation patterns and the area dedicated to crop production in the future as well. Favorable market conditions have led to an increase in corn (Zea mays) area nationally by almost 20\% from 2006 to 2007 (Landis et al., 2008 and USDA, 2008) reaching a peak in 2010 (Plourde et al., 2013 and USDA, 2011a). A parallel development has been the availability of additional cropland for cultivation because of the decrease in the maximum area enrolled in the Conservation Reserve Program (Westcott, 2007). Farmer acceptance for using cellulosic feedstock has also grown (James at al., 2010), bringing new energy crops into the mix. 


\subsection{Mapping cropland areas and crop rotation patterns}

The United States Department of Agriculture (USDA) tracks agricultural activity in the US at scale of individual counties as part of the census of agriculture (USDA, 2009). The analysis of these data provides valuable information on US farms, ranches and feedlots and the farmers who operate them. Due to the expensive and time consuming nature of this activity, new data are made available only once every five years. The coarse spatial resolution and sparse temporal availability precludes the derivation of fine resolution $(<1 \mathrm{ha})$ annual crop production and rotation maps. The other major source of agricultural activity monitoring is the Acreage (USDA, 2011b), which aggregates crop production information from surveying nearly 3 million ha of agricultural land. While produced annually, this information is provided at the scale of US states, and is therefore unsuitable for fine resolution mapping.

Remotely-sensed data provide a way to mitigate the temporal frequency and spatial resolution limitations of ground based surveys. National scale corn and soybean (Glycine max) area estimates obtained from Moderate Resolution Imaging Spectroradiometer (MODIS) data at $250 \mathrm{~m}$ and $500 \mathrm{~m}$ resolution compare favorably with the USDA's National Agricultural Statistics Service (NASS) survey based area estimates (Change et al., 2007 and Wardlow and Egbert, 2008). While the MODIS satellite follows a rapid 16-day repeat cycle and the average farm size of 175 ha (Dimitri et al., 2005) far exceeds MODIS resolution, its utility in determining crop rotations is limited because crop rotations for individual fields in a farm can vary at sub-MODIS resolutions. This limitation is even more evident when using the 1-km resolution Advanced Very High Resolution Radiometer (AVHRR) data to classify crop cover types (Jakubauskas et al., 2002). A capable alternative is the USDA NASS Cropland Data Layer (CDL) which classifies more than 100 crop types in coterminous US at a resolution of 30/56m (Boryan et al., 2011). The 
oldest CDL product dates back to 1997 for North Dakota. While initially focused on the major crop producing states, the program has expanded to cover the conterminous US from 2008 onwards. The CDL has been used widely in land-cover change detection (Wright and Wimberly, 2013), watershed runoff modeling (Srinivasan et al., 2010), habitat monitoring (Meehan et al., 2010) and in process-based models for biofuel feedstock production analysis (Gelfand et al., 2013).

The simulation of biomass yields, evapotranspiration, runoff and related outcomes in a processbased model, are affected by soil properties, crop types and climatic conditions (Izaurralde et al., 2007). Therefore, it is critical to get both the spatial extent and temporal coverage of crop rotation patterns right for land-cover change analysis and ecosystem modeling. A variety of approaches have been developed to construct crop rotation patterns. These approaches fall into three categories: (a) Methods based on a mathematical framework: Crop rotations are modeled either as a transition matrix with implicit path dependency (Castellazzi et al., 2008) or are based on linear programming models (Detlefsen and Jensen, 2007). While these methods attempt to incorporate expert knowledge on suitable crop rotation patterns, they usually do not include the market drivers that influence farmer's decisions on an annual basis. Instead, they are more useful for exploratory modeling studies (Dogliotti et al., 2003). (b) Crop rotation patterns determined through consultation with field experts, USDA extension agents or from NASS survey data (Arabi et al., 2008): Unless the study area is a small farm, it is difficult to obtain spatially explicit information on land-cover and land-cover change through this approach. Therefore, approaches that rely on expert knowledge can be difficult to scale without prior information on what crop rotations are practiced in a region (Xiao et al., 2014), and are susceptible to biases or gaps in that information. (c) Crop rotation patterns determined through remotely-sensed data like CDL: 
While spatially explicit and generally accurate for major production crops in the US, combining multiple years of CDL to get crop rotation information results in a large number of factorial crop combinations (Stern et al., 2012). The large number of crop rotations are combined with a wide range of other input choices for chemicals and irrigation to generate management scenarios. Modeling frameworks face computational bottlenecks in efficiently simulating a large number of management scenarios. Some modeling studies try to bypass this limitation by selecting far fewer crop rotations based on their area (Srinivasan et al., 2010 and Muth et al., 2013). These studies only use a subset of all existing crop rotations and do not quantify the error introduced in the output as a result. Others greatly simplify each crop rotation pattern to focus on general trends i.e. whether the crop rotation is a monoculture or alternating (biannual, triennial, and quadrennial) in nature (Stern et al., 2008, Mehaffey et al., 2011, Secchi et al., 2011 and Plourde et al., 2013). Further, no attempt has been made in existing literature to produce a parsimonious selection of representative crop rotations for a region with area estimates comparable to NASS data.

\subsection{Objectives and Preview}

The objectives of this research are to: (a) quantify the diversity of crop rotation patterns and (b) to examine land-cover transitions occurring in the agronomically productive and ecologically sensitive parts of the WCB. In order to achieve these objectives, we developed a novel twoparameter algorithm for identifying crop rotation patterns in the WCB during a three year period (2010 to 2012). We examined the tradeoff between number of representative crop rotations and accuracy by comparing estimated area against CDL and NASS crop area data. A sensitivity analysis of the algorithm parameters was conducted to assess its performance across the study 
region. Finally, we used the crop rotation product to estimate grassland conversion to crop cultivation in a wetland dominated part of the WCB. In summary, we examined the effectiveness of the algorithm in reducing the number of crop rotation patterns required to map and model each state by several orders of magnitude, while adequately capturing crop area and land-cover change trends.

\section{Materials and Methods}

\subsection{Study Area}

Annual crop production is the dominant land-use in our study area comprising the WCB states of North Dakota (ND), South Dakota (SD), Nebraska (NE), Minnesota (MN) and Iowa (IA). While accounting for more than two-fifths of the corn and soybean area planted nationally in 2012 (http://quickstats.nass.usda.gov/), these states also overlap the Prairie Pothole Region (PPR), an ecologically sensitive wetland landscape (Johnson et al., 2010). CDL data for all five states in the WCB has been available since 2006, providing seven years of land-use/cover information for analysis. Starting in 2007, CDL data are provided statewide with cloud-free coverage. For years prior to 2007, CDL data includes metadata files with information on level and extent of cloud contamination.

\subsection{Cropland Data Layer}

USDA classifies crop cover types in conterminous US using satellite imagery from a variety of sources including MODIS, Advanced Wide Field Sensor (AWiFS) and Landsat Thematic Mapper (TM). To produce the annual CDL product, ground truth information on land-use, area 
and field boundaries is obtained from the USDA farm service agency's Common Land Unit (CLU) dataset. Subsequently, a statewide land-cover classification is produced by performing a supervised classification of the geo-referenced and orthorectified satellite imagery, using the digitized field segments as training samples. By using a comprehensive national ground truth dataset, CDL data achieves producer and user accuracies between $80 \%$ - 95\% for major agricultural crops that are traded on the US commodity markets, including: corn, soybean, winter wheat (Triticum aestivum), cotton (Gossypium hirsutum), spring wheat (Triticum aestivum) and durum wheat (Triticum durum). Crop area estimates obtained by counting pixels in the CDL data compare favorably with survey based estimates from NASS (Plourde et al., 2013). The information from the CLU dataset pertains only to agricultural land-cover and is supplemented by the National Elevation Dataset (NED), National Land Cover Dataset (NLCD) percent tree cover and percent impervious products for non-agricultural land-cover classes.

\subsection{DATA PROCESSING}

We downloaded the CDL raster data for the WCB states from http://nassgeodata.gmu.edu/CropScape/ (Han et al., 2012). While CDL data are available for the conterminous US starting from 2008, we chose to present our algorithm results and analysis for a three year period (2010 to 2012). Most crop rotations in the US Midwest do not exceed this duration (Plourde et al., 2013). However, the algorithm can be run for any number of years pending availability of CDL data. The resolution of CDL between 2006 and 2009 is 56m, and can be resampled to $30 \mathrm{~m}$ resolution. The rasters were acquired in Albers conical equal area projection, one file for each year for each state. Each CDL raster is thematic with a unique identifier representing discrete features of crop cover type or in the absence of cropping, the 
land-cover. A generically defined NonAg land-cover class was created from all non-agricultural land-cover classes in CDL. The CDL classes considered to be non-agricultural included: pasture/hay (CDL code 181), shrubland (code 64), grassland herbaceous (code 171), sod/grassseed (code 59), clovers/wildflowers (code 58), other hay (code 37) and pasture/grass (code 62). This was done because of low confidence in the accuracy of CDL to distinguish between various grassland categories (grass hay, grass pasture, hay/pasture and native grassland). The CDL documentation also suggested using NLCD for all non-agricultural land-cover change analysis $^{1}$.

Of the several thousand unique crop rotations that exist for each state (Table 1), we wanted to select a subset of representative crop rotations which while much fewer in number, provide area estimates comparable to CDL. We present the Representative Crop Rotations Using Edit Distance (RECRUIT) algorithm to derive representative crop rotations using the CDL. The algorithm was coded in Python and used the ArcPy API from ArcGIS ${ }^{\circledR}$ to perform geospatial analysis. The fully automated algorithm operates as follows (Fig. 1):

1. For each state, $\mathrm{CDL}$ pixels with the same spatial co-ordinates, but different annual time stamps $\left(2010,2011\right.$ or 2012) were combined in $\operatorname{ArcGIS}^{\circledR}$, producing a unique output value for each unique combination of input values. Each of the output values denotes a distinct crop rotation. Since there are nearly 100 crop types in the CDL database and we analyzed three years of data, the number of possible crop rotations is nearly 1 million $\left(100^{3}\right)$. However, when calculated using multi-year CDL data, there are 13,588 crop rotations ranging from 0.09 ha ( 1 pixel) to 7.5 million ha $(83,278,895$ pixels) in size (Table 1$)$ in the WCB. The number of unique crop rotations in the WCB is not the sum of its constituent 
states because the same crop rotation can exist in different states. The pixels corresponding to a particular crop rotation need not be spatially contiguous and can have NonAg as a land-cover type.

2. For each crop rotation, we computed its area by multiplying the cell size of the raster $(30 \mathrm{~m}$ $\mathrm{x} 30 \mathrm{~m}$ or $0.09 \mathrm{ha}$ ) with the number of pixels corresponding to that rotation. We also computed the percentage of the total cultivated area occupied by that crop rotation and then rearranged the crop rotations by descending order of area.

3. To determine the representative crop rotations, we selected crop rotations starting from the one with the largest area, till either one of two threshold parameters was exceeded. The first parameter is the cumulative acreage threshold $(\alpha)$, defined as the percentage of the total area occupied by the rotations selected thus far. A value of $0 \%$ for this parameter implies that no crop rotation will be selected, while all crop rotations will be selected at $100 \%$. The second parameter is the marginal increase threshold $(\beta)$, defined as the marginal increase in area by selecting the current rotation. To assess parameter sensitivity, the algorithm was run for ten cumulative acreage threshold values $(0 \%, 15 \%, 30 \%, 45 \%, 60 \%, 75 \%, 80 \%$, $90 \%$ and $100 \%)$, and eight marginal increase threshold values $(0 \%, 0.5 \%, 1 \%, 5 \%, 10 \%$, $20 \%, 60 \%$ and $100 \%)$.

4. After selecting the representative rotations, a large number of rotations remained unaccounted for. Therefore, we used the reclassify command in $\operatorname{ArcGIS}{ }^{\circledR}$ to convert each of them to a rotation from the representative list they were most similar to. The edit distance 
metric is used to quantify the similarity by counting the minimum number of insertions, deletions and substitutions required to transform one crop rotation into another (Ristad and Yianilos, 1998). For example, consider the following three year crop rotations: cornsoybean-corn and a continuous corn rotation. These differ in the middle year, and can be made the same by converting from soybean to corn or vice versa. Therefore the edit distance for this example would be one. This step increased the accuracy of the representative crop rotations and is unique to our algorithm. However, it was also the most time consuming part of RECRUIT, since its performance is directly proportional to the square of the number of years of CDL data used as input. In case of a tie, we reclassified the rotation to the representative rotation with the larger area. While we considered crop rotations that are mirror images of one another: e.g. corn-soybean-corn and soybean-cornsoybean to be unique, the RECRUIT tool can optionally merge them.

5. After reclassifying all the remaining rotations, RECRUIT can create a wall-to-wall product by merging the crop rotation raster with non-agricultural land-cover pixels (forests, grasslands, wetlands and urban areas) from the CDL rasters. 


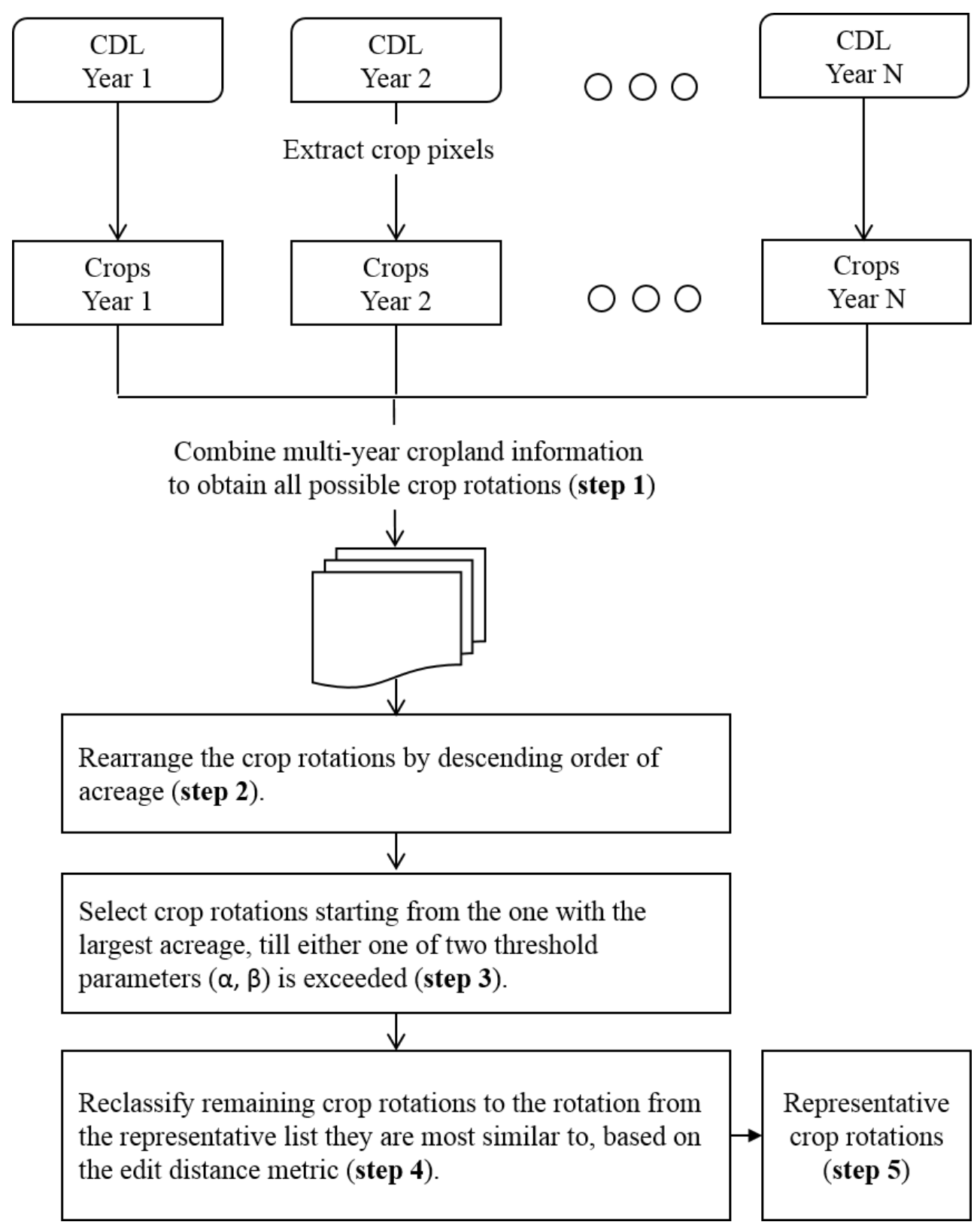

Fig. 1. Flowchart of the RECRUIT algorithm. Individual steps of the algorithm are indicated in bold font. 


\section{Table 1}

Number of unique crop rotations by state and region.

\begin{tabular}{lccccc}
\hline & Number of & Largest & Smallest & \% of cultivated \\
& rotations & Largest rotation & rotation & rotation & area occupied by \\
& & & $($ ha) & (ha) & largest rotation \\
\hline ND & 9,619 & soybean-spring wheat-soybean & 345,046 & 0.09 & $4.1 \%$ \\
\hline SD & 6,091 & corn-soybean-corn & 942,059 & 0.09 & $15.4 \%$ \\
\hline NE & 3,906 & corn-soybean-corn & $1,410,024$ & 0.09 & $19.5 \%$ \\
\hline MN & 5,554 & corn-soybean-corn & $1,774,178$ & 0.09 & $22.9 \%$ \\
\hline IA & 1,108 & corn-soybean-corn & $3,077,256$ & 0.09 & $33.4 \%$ \\
\hline WCB & 13,588 & corn-soybean-corn & $7,495,100$ & 0.09 & $19.3 \%$ \\
\hline
\end{tabular}

We computed the accuracy of the crop rotation product as the percentage of pixels for which our crop rotation product differs in its land-cover class compared to the CDL, averaged across multiple years of rotation. For example, consider the following three year rotations: cornsoybean-corn and soybean-soybean-corn occupying 100 and 20 ha respectively. If we merge the second rotation into the first, we will get a representative rotation of corn-soybean-corn. Our accuracy for the new rotation would be $94.4 \%$, because out of the total area of 360 ha over the 3 year duration, only the soybean fields spread over 20 ha in the first year would have been incorrectly reclassified as corn, while the remaining 340 ha are classified correctly. If we did not merge the second rotation into the first and used the first rotation to map the entire area, the soybean-soybean-corn rotation spread over 60 ha across the three-year duration would be unaccounted for, leading to an accuracy of $83.3 \%$. Therefore, the marginal increase in accuracy 
by merging the second rotation into the first is equal to the difference in accuracies for the two scenarios or $11.1 \%$.

\section{Results and Discussion}

\subsection{Crop rotation area variation across the $W C B$}

The mechanics of the RECRUIT algorithm can be better understood by examining the variation in crop rotation area across the WCB. We plotted the marginal contribution of each crop rotation to the total cultivated area in Fig. 2. A gradual increase, as is the case in North Dakota, indicates a wider diversity of crop rotations as compared to Iowa where the largest crop rotation by area accounts for one-third of the cultivated area (Table 1), while the smallest crop rotation in each state reflects the pixel size (0.09 ha). The RECRUIT algorithm is based on selecting the crop rotations with the greatest marginal contribution as representative of the entire set. 


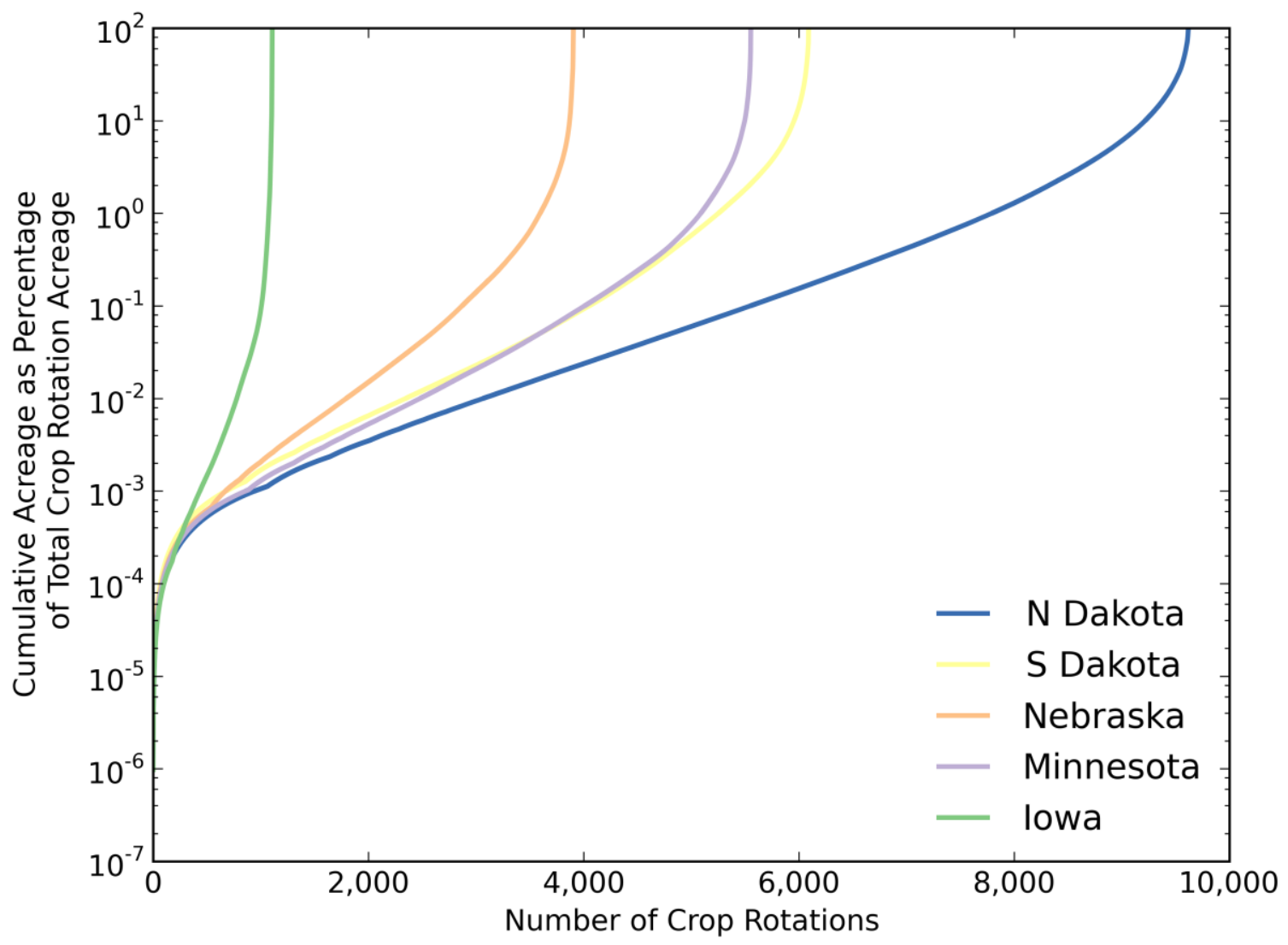

Fig. 2. Marginal contribution of each crop rotation to the total cultivated area of the state.

The crop rotations representative of the WCB from 2010 to 2012 were mapped (Fig. 3). They were selected by running the RECRUIT algorithm, with parameter values $\alpha(75 \%)$ and $\beta(5 \%)$. Each pixel in the representative crop rotation raster had three attribute values: one land-cover for each year from 2010 to 2012. Overall, $75.2 \%$ of the pixels in the representative crop rotation product had the same land-cover as the CDL data from which it was derived. The area estimate for each representative crop rotation, listed by state, is presented (Table 2). Nearly 24.2 million ha or $62.5 \%$ of the total cultivated area is occupied by corn-soybean-corn and soybean-cornsoybean rotations. From an agronomic point of view these rotations are the same. However, were 
the latter rotation merged into the former, the effective area devoted to corn production would increase, thus reducing the total area devoted to soybean production by nearly 2 million ha/yr. Several crop rotations, e.g. continuous soybean were shown to have zero area in several states (Table 2). This does not imply that no such crop rotation exists in that state. Instead, its area was low enough for RECRUIT to combine it with a higher frequency crop rotation based on their similarity.

\section{Table 2}

Crop rotations from fig. 2 with area figures for each state and arranged in descending order of its total area in the WCB. Crop names are given as abbreviations: Swht - Spring Wheat, Soyb Soybean, Cano - Canola. NonAg includes all non-agricultural land-cover classes that are in rotation with crops for this three year period.

$\begin{array}{lrrrrrrrr}2010 & \text { 2011 } & \text { 2012 } & \text { ND } & \text { SD } & \text { NE } & \text { MN } & \text { IA } & \text { WCB } \\ & & & & & & & \end{array}$




\begin{tabular}{llrrrrrrr}
\hline Soyb & Corn & Soyb & 766,928 & $1,511,005$ & $1,458,197$ & $2,369,365$ & $4,146,642$ & $10,252,137$ \\
\hline Corn & Corn & Corn & 0 & 389,559 & $1,662,749$ & 707,676 & $1,301,801$ & $4,061,784$ \\
\hline Soyb & Swht & Soyb & $2,457,665$ & 0 & 0 & 536,270 & 0 & $2,993,934$ \\
\hline Swht & Swht & Swht & $1,698,744$ & 0 & 0 & 0 & 0 & $1,698,744$ \\
\hline Soyb & Corn & Corn & 0 & 331,269 & 547,324 & 485,527 & 0 & $1,364,121$ \\
\hline Swht & NonAg & Swht & $1,150,006$ & 0 & 0 & 0 & 0 & $1,150,006$ \\
\hline NonAg & NonAg & Corn & 0 & 717,099 & 0 & 0 & 0 & 717,099 \\
\hline Corn & Corn & Soyb & 0 & 180,132 & 424,756 & 0 & 0 & 604,889 \\
\hline Swht & Soyb & Swht & 511,866 & 0 & 0 & 0 & 0 & 511,866 \\
\hline Soyb & Soyb & Corn & 214,859 & 186,577 & 0 & 0 & 0 & 401,437 \\
\hline Swht & Canola & Swht & 320,383 & 0 & 0 & 0 & 0 & 320,383 \\
\hline Soyb & Soyb & Soyb & 314,193 & 0 & 0 & 0 & 0 & 314,193 \\
\hline NonAg & Corn & Soyb & 0 & 241,432 & 0 & 0 & 0 & 241,432 \\
\hline Swht & Soyb & Soyb & 156,184 & 0 & 0 & 0 & 0 \\
\hline
\end{tabular}

There are significant land-cover changes taking place in the WCB as a result of grassland conversion to cultivated areas (Wright and Wimberly, 2013). Three representative crop rotations were found to have a NonAg land-cover class for at least one year (Fig. 3, Table 2). This could either indicate a fallow year which was misclassified as grassland or it could be Conservation Reserve Program (CRP) land coming out of enrollment. Much less frequently, the NonAg class could denote a land-cover that is highly unlikely to be part of a rotation e.g. urban. Using the edit-distance metric to combine low frequency rotations with the representative ones automatically adjusts for the rotations that are probably misclassified. 


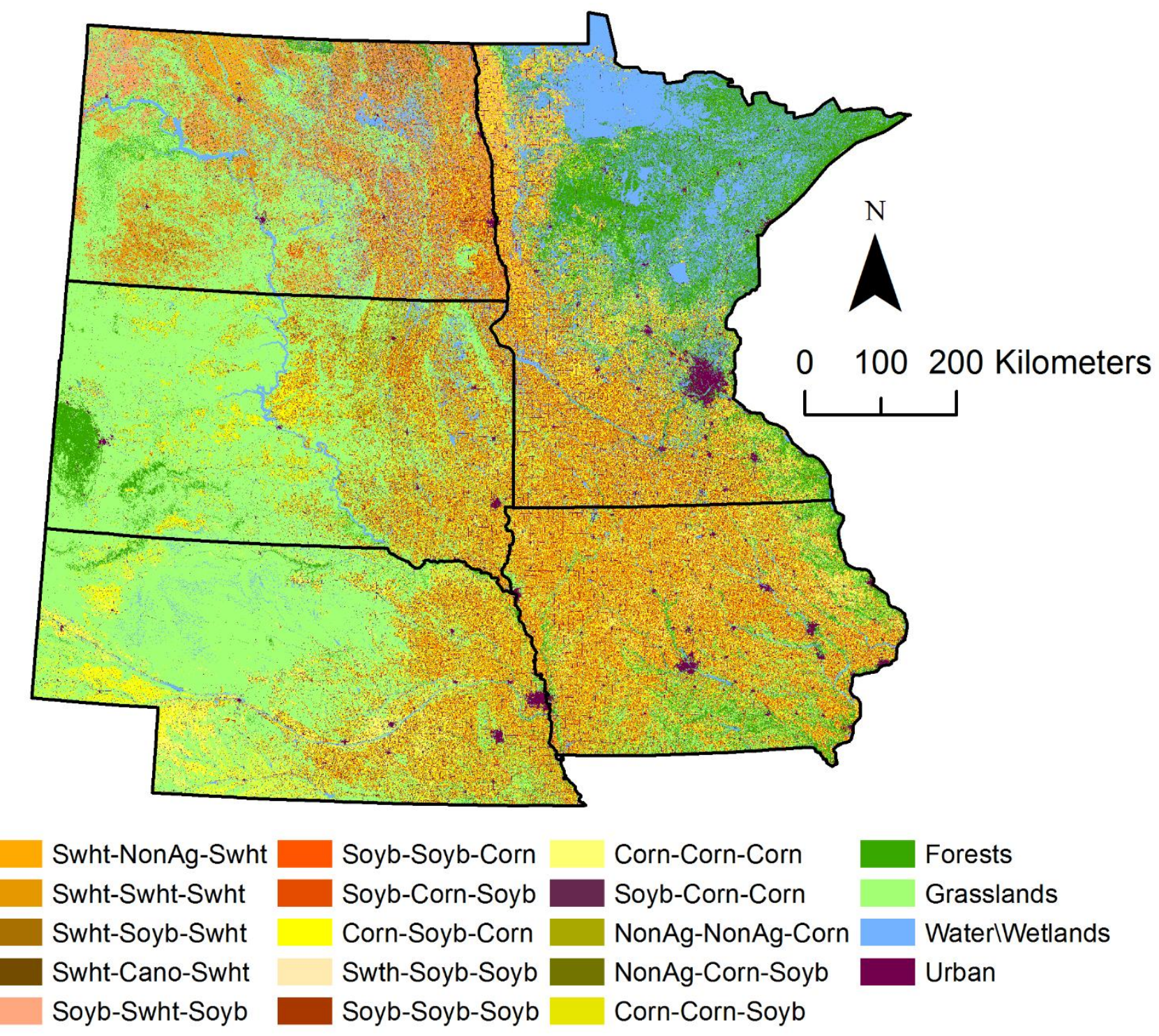

Fig. 3. Crop rotation patterns across the WCB from 2010 to 2012. Crop names are given as abbreviations: Swht - Spring Wheat, Soyb - Soybean, Cano - Canola. NonAg includes all nonagricultural land-cover classes that are in rotation with crops for this three year period. 


\subsection{Accuracy of representative crop rotations}

Regional variability in the choice and area of crops planted by farmers manifested itself in the observed crop rotation patterns. In Iowa, selecting two representative crop rotations (cornsoybean-corn and soybean-corn-soybean) achieved $\sim 85 \%$ accuracy (Fig. 4). In contrast, more than 100 representative crop rotations were needed to map North Dakota at a similar accuracy (Fig. 4). In all, 400 data points were plotted, representing RECRUIT results for 80 combinations of $\alpha$ and $\beta$ for each of the five states. The number of visible data points in fig. 4 is less than 400 because several $\alpha$ and $\beta$ combinations resulted in the same accuracy. The logarithmic $\mathrm{x}$-axis implies that any additional accuracy gains involve a tradeoff, thereby greatly increasing the number of representative crop rotations. For example 1,108 crop rotations can map Iowa at 100\% accuracy (Table 1), compared to just two for $85 \%$ accuracy. 


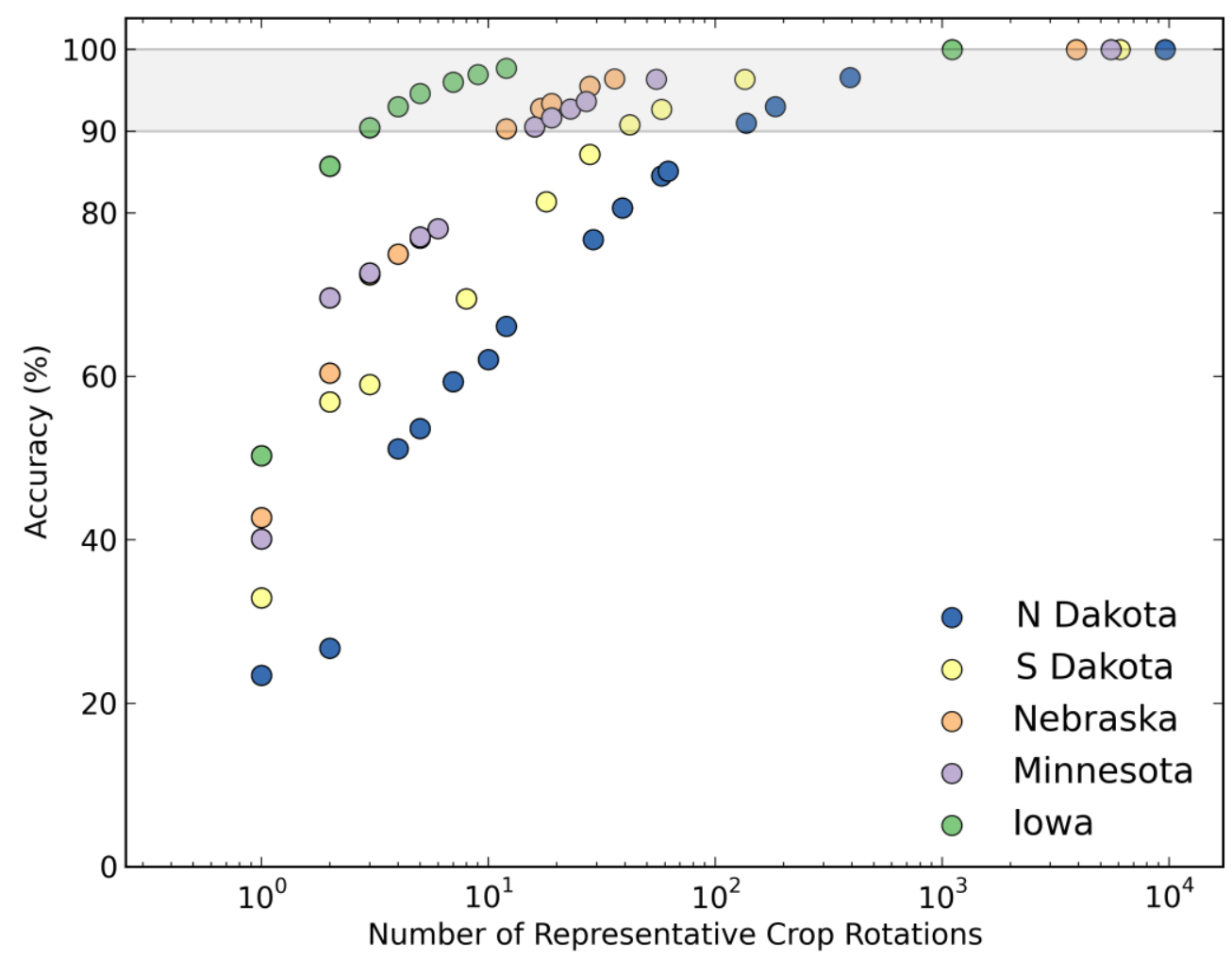

Fig. 4. Tradeoff between product accuracy and the number of representative crop rotations selected for each state in the WCB. The gray band indicates the number of representative crop rotations for different combinations of $\alpha$ and $\beta$, with accuracy exceeding $90 \%$.

The accuracy of the WCB crop rotation product varies as a function of the two threshold parameters (Fig. 5). At one extreme, on the lower left corner of the heatmap, we did not select any crop rotation resulting in an accuracy of $0 \%$. On the lower right corner, we selected all crop rotations as representative resulting in an accuracy of $100 \%$. Between these two extremes, the number of representative crop rotations varies by three orders of magnitude. The isolines for accuracy levels of $60 \%, 70 \%, 80 \%$ and $90 \%$ indicate the $\alpha$ and $\beta$ values for attaining specific accuracy targets. Notably, part of the $60 \%$ isoline is perfectly horizontal. This is because no crop 
rotation in the $\mathrm{WCB}$ has a marginal contribution exceeding $60 \%$ of the area of the representative crop rotations selected before it. Since RECRUIT selects representative crop rotations till either the cumulative acreage or the marginal increase in acreage threshold is exceeded, at high values of $\alpha(>60 \%)$, we need to select a $\beta$ value of $5 \%$ or lower to obtain an accuracy exceeding $80 \%$ (Fig. 5). For lower values of $\alpha$, the value of $\beta$ is not as much of a constraining factor for product accuracy.

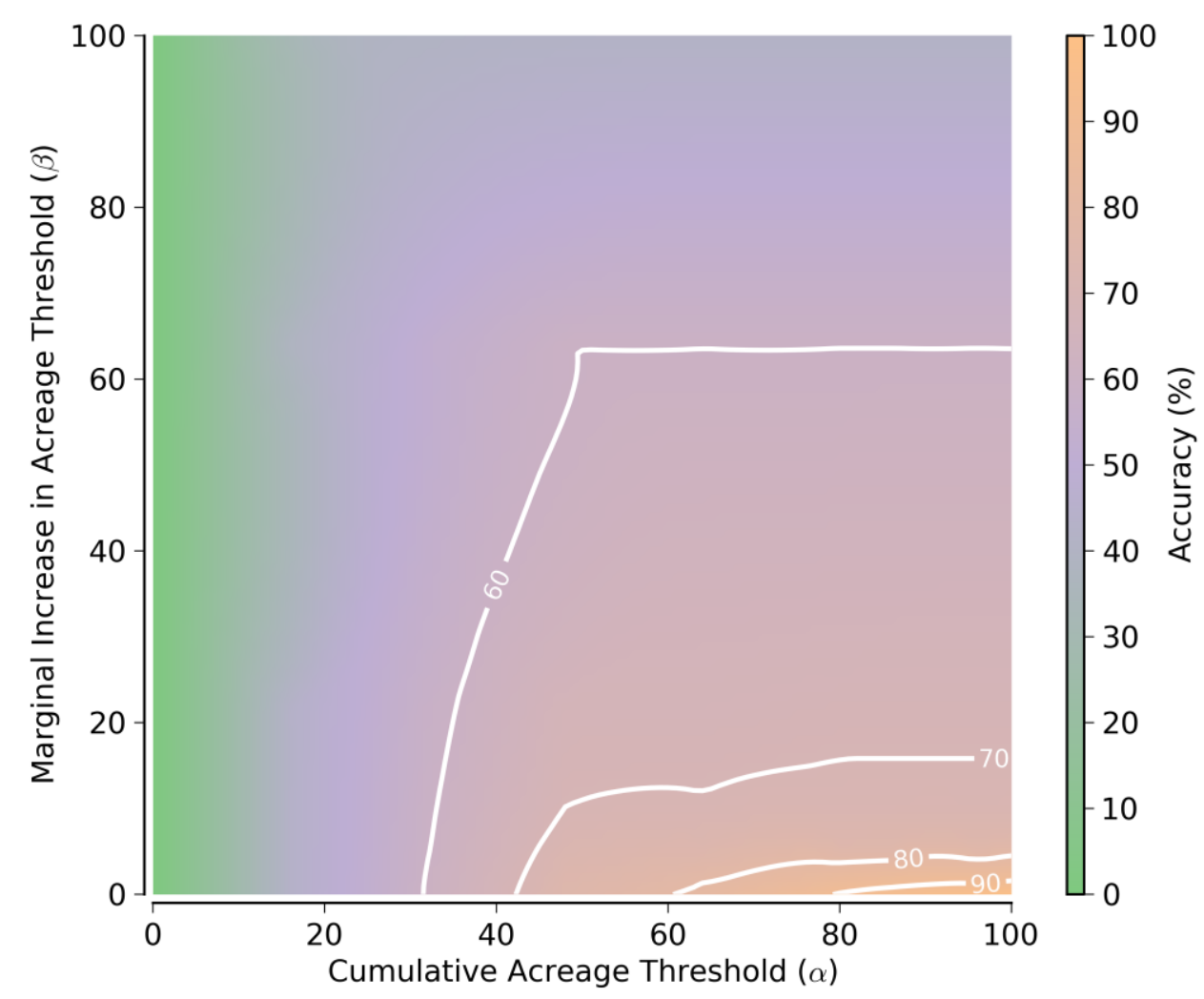

Fig. 5. Variation in accuracy of the WCB crop rotation product as a function of $\alpha$ and $\beta$ parameters used in RECRUIT. The contours indicate the isolines for accuracy levels of $60 \%$, $70 \%, 80 \%$ and $90 \%$. 
Merging the low frequency crop rotation with the representative set increased the accuracy of the crop rotations product (Fig. 6). Each of the eight panels (A to H) plots the percentage marginal increase in accuracy for a distinct value of the marginal increase in acreage threshold $(0 \%, 0.5 \%$, $1 \%, 5 \%, 10 \%, 20 \%, 60 \%$ and $100 \%)$ while the cumulative acreage threshold varies. In each panel, the percentage marginal increase in accuracy rose from $0 \%$ when $\alpha$ is $0 \%$ to around $25 \%$ or slightly higher when $\alpha$ is $15 \%$. The higher percentage marginal increase for Nebraska rather than Iowa can be understood on the basis of the much greater diversity and number of crop rotations in Nebraska (Fig. 2). There are simply more crop rotations to merge with the representative set in the case of Nebraska. In panel A, the percentage marginal increase in accuracy dropped to $0 \%$ when $\alpha$ is $100 \%$ because all crop rotations have been selected as representative at that point, leaving no additional crop rotations to merge.

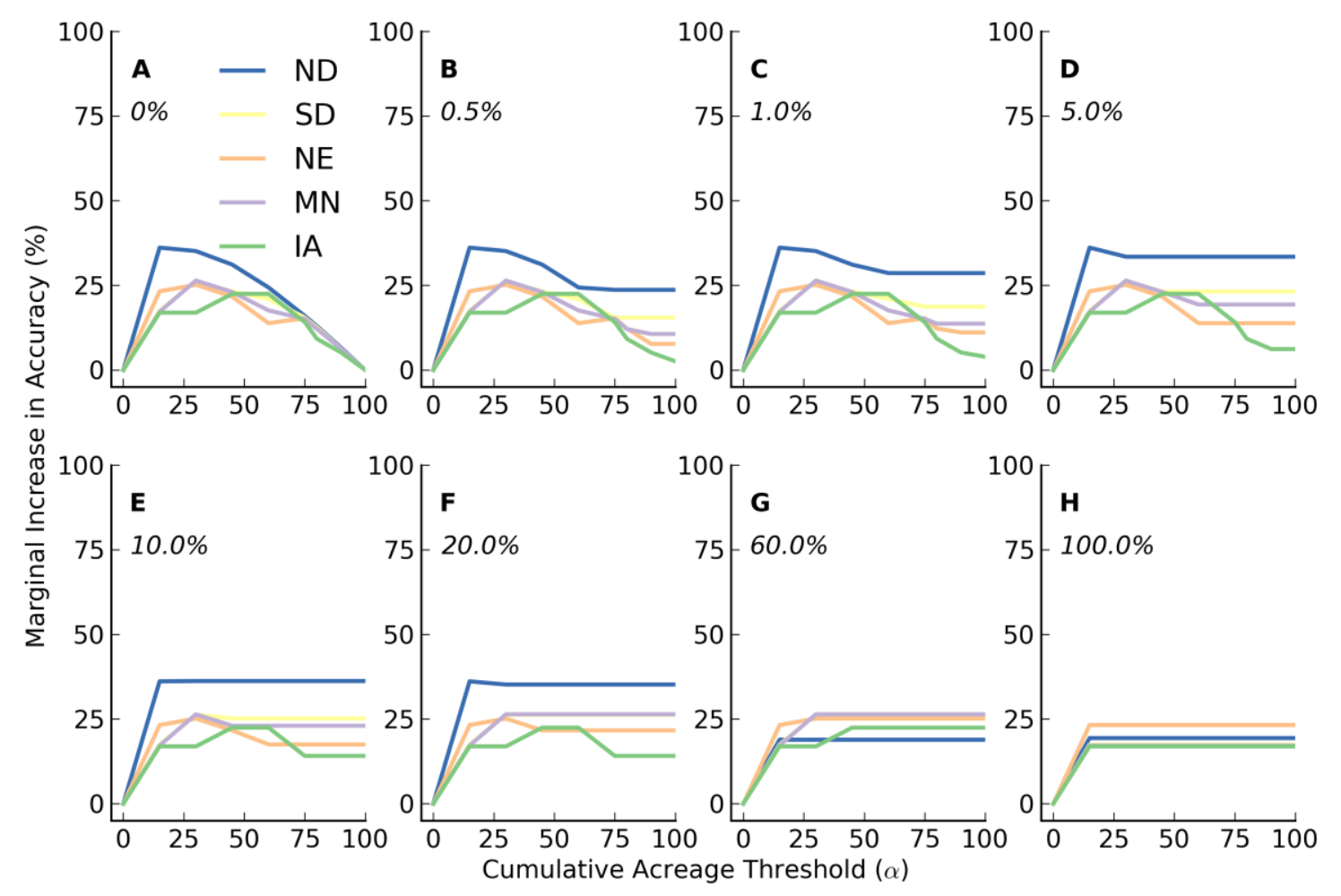


Fig. 6. Marginal increase in accuracy of crop rotation product for each state, obtained by combining all crop rotations with the representative crop rotations. Each of the eight panels shows a distinct value of the marginal increase in acreage threshold $(\beta)$.

While the percentage marginal increase in accuracy puts a numeric estimate on the benefit of merging all crop rotations with the representative set, it is useful to look at the percentage accuracy of the product as it will ultimately drive our selection of RECRUIT parameter values. Full accuracy was achieved when $\alpha$ is $100 \%$, corresponding to a $0 \%$ marginal increase in accuracy (Fig. 7(A)). Consistent with fig. 4, accuracy scores are generally the lowest for North Dakota and highest for Iowa. Also consistent with observations in fig. 6, percentage accuracy started to plateau sooner as the value of $\beta$ increases.

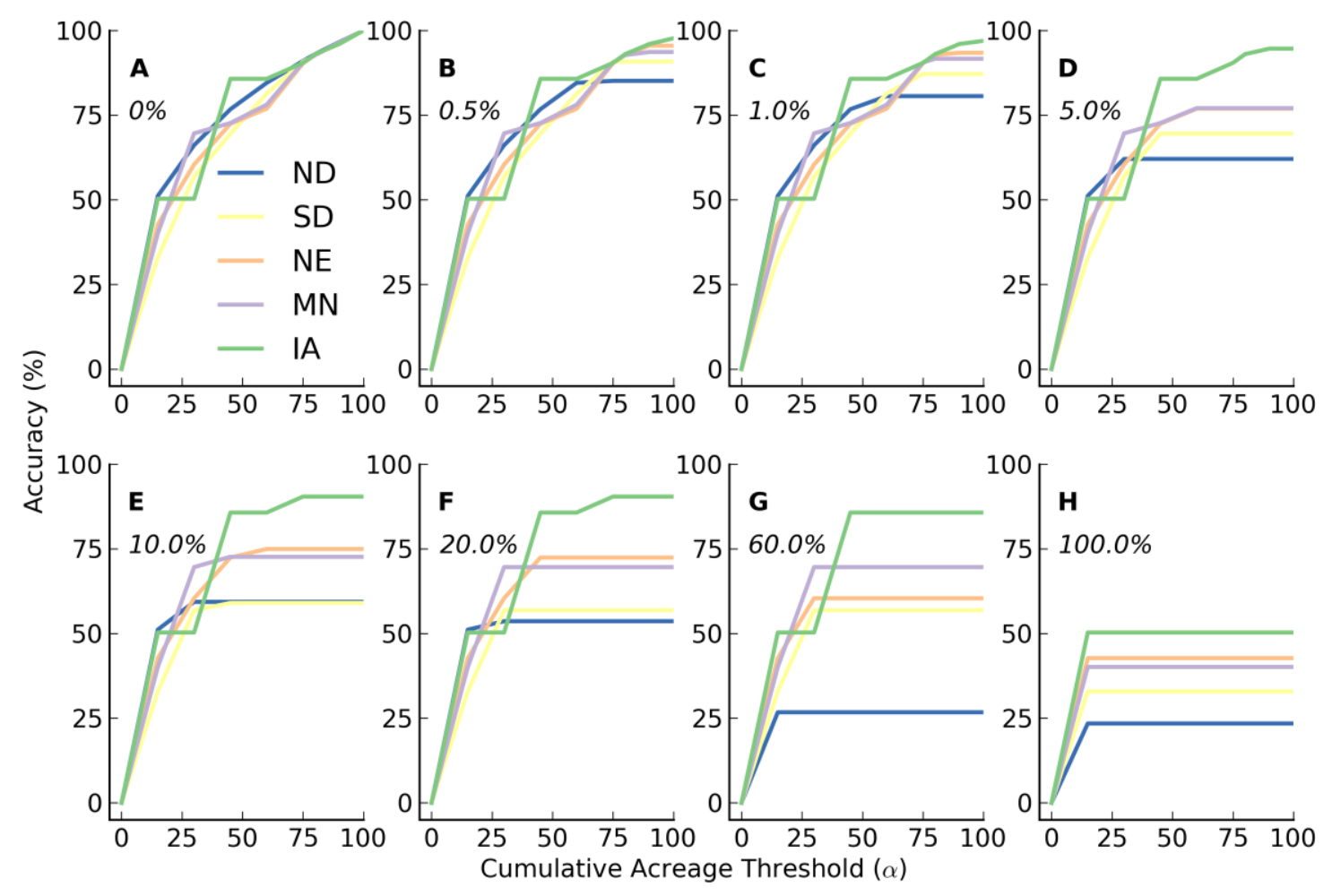


Fig. 7. Accuracy of crop rotation product for each state, obtained by combining all crop rotations with the representative crop rotations. Each of the eight panels shows a distinct value of the marginal increase in acreage threshold $(\beta)$.

Crop area estimates obtained by counting pixels in the CDL are typically downward biased due to imperfect classification, cloud contamination or interference from neighboring pixels (Townshend et al., 2000). Since the crop rotation product is a simplification of a time-series of CDL rasters, we compared area estimates from the CDL and our crop rotation product against NASS survey data. We observed a $3 \%$ average difference in corn area and $4.1 \%$ average difference in soybean area from 2010 to 2012 between the 13,588 crop rotations in CDL (Table 1) and NASS (Fig. 8). The corresponding differences for a crop rotation product with 82 representative rotations and overall accuracy exceeding $90 \%$, was $7.6 \%$ for corn and $9.24 \%$ for soybean. Reducing the number of representative crop rotations to 15 increased the average difference in area to $21.7 \%$ for corn and $18.4 \%$ for soybean (Fig. 8). 

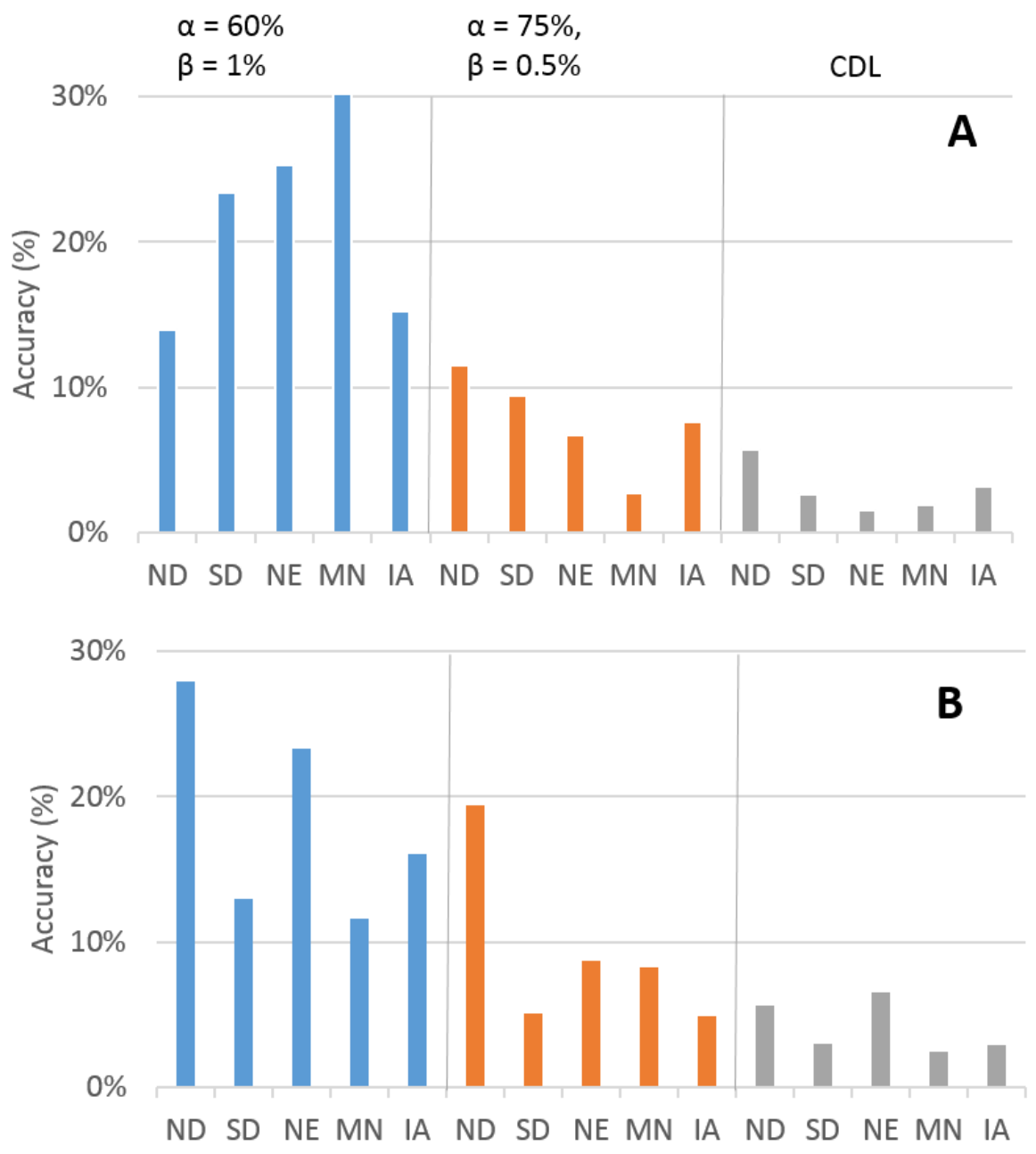

Fig. 8. Magnitude of average difference in crop area from 2010 to 2012 between the crop rotation product and NASS (blue and orange bars), and CDL layers for each year and NASS (gray bars). Panels A and B show the average difference for corn and soybean area respectively. The $\alpha$ and $\beta$ parameter values corresponding to the blue and gray bars are shown on top of panel A. 


\subsection{PRONOUNCED SHIFTS FROM GRASSLAND TO CULTIVATED AREAS IN THE PRAIRIE POTHOLE REGION}

Crop rotation patterns can provide information on land-cover change happening in ecologically sensitive areas. We used the crop rotation product identified in fig. 8 (82 crop rotations with overall accuracy $>90 \%, \alpha(75 \%), \beta(0.5 \%))$ to estimate grassland conversion to specific crop rotation patterns in the PPR. Recently, Wright and Wimberly (2013) reported that contemporary grassland conversion to corn and soybean cropping (GRCS) in the PPR is concentrated within a $500 \mathrm{~m}$ area surrounding wetlands. If land-cover conversion in the PPR was induced by increased demand for corn and soybean, we should be able to observe intensive cultivation of corn and soybean in the area. To test this hypothesis, we selected representative crop rotations from 2010 to 2012 for the PPR with an overall accuracy of around 90\%. Using the CDL, we found nearly 147,267 ha undergoing GRCS in close proximity to wetlands between 2010 and 2012. Of the lands undergoing GRCS, nearly $38 \%$ was devoted to continuous corn or continuous soybean cropping and another $27 \%$ was covered by alternating corn and soybean rotations (Table 3 ). These patterns are very surprising especially given the widespread consensus that continuous cropping of soybean for more than two years is not a viable choice on account of enhanced parasite activity (Secchi et al., 2011).

\section{Table 3}

Crop rotations in the GRCS pixels in PPR. The GRCS pixels lie within a 500m radius of wetlands. Soybean is abbreviated as Soyb.

\begin{tabular}{llll}
\hline $\mathbf{2 0 1 0}$ & $\mathbf{2 0 1 1}$ & $\mathbf{2 0 1 2}$ & Area (ha) \\
\hline Soyb & Soyb & Soyb & 39,173
\end{tabular}




\begin{tabular}{llcc}
\hline Corn & Corn & Corn & 16,767 \\
\hline Soyb & Corn & Soyb & 25,846 \\
\hline Corn & Soyb & Corn & 13,916
\end{tabular}

\section{Discussion of limitations and future work}

The RECRUIT algorithm is temporal range agnostic. While we present results for crop rotations from 2010 to 2012, it is possible to use CDL rasters starting from 2008 for any state in the coterminous US, and going back to 1997 for states like North Dakota. Using RECRUIT over longer time periods ( $>3$ years), can produce patterns that include repetitions of the same crop rotation, e.g. a corn-soybean rotation repeated thrice over a six year period. Our approach can be enhanced in the future by initially identifying the repetitions within a crop rotation pattern and subsequently applying the edit-distance based approach.

The methodology, software and input data used to produce CDL has evolved during the fifteen year history of the product and it is important to understand how that can affect the accuracy of the derived crop rotation product. First, from 2006 to 2009, 56m resolution AWiFS sensor data was used to produce the CDL. An imagery comparison between the two sensors (AWiFS and Landsat-5 TM) shows that they produce equivalent results for agricultural and forestry applications despite the differences in the design of the two sensors (Johnson, 2008) and the radiometric degradation over time of the AWiFS sensor (Goward et al., 2012). Second, because of the relatively large swath width of the AWiFS sensor $(740 \mathrm{~km})$, angular effects arising from variable solar and viewing geometry can potentially cause significant changes in observed reflectance without any change in land-cover, phenological status or vegetation condition (Gao et 
al., 2013). Wheat shows stronger angular effects than corn in both red and NIR bands (Gao et al., 2013), perhaps contributing to its lower producer/user accuracies in the CDL. Third, land-cover change analysis using CDL data prior to 2006 can be subject to errors because of a change in processing software and algorithms in 2006 (Boryan et al., 2011). Fourth, while CDL has producer and user accuracies between $85 \%-95 \%$ for major row crops like corn and soybean, its accuracies are quite a bit lower for specialty crops, fruits and vegetables. Finally, CDL performs poorly in distinguishing between the subtle spectral signature variations amongst the various non-agricultural land-cover classes, especially in the grassland category: pasture/hay, fallow/idle cropland and native grassland. It is recommended to use NLCD for land-cover change analysis involving non-agricultural or grassland/pasture categories ${ }^{1}$.

Several opportunities exist to use the crop rotation products generated by RECRUIT. Meehan et al. (2013), used the product to examine the changes in ecosystem services due to land-use conversion from annual to perennial biofuel feedstock in the US Midwest. Zhang et al. (2014), combined the product with other spatially explicit data (climate, soils and topography) to examine the sensitivity of an agro-ecosystem model to soil data input. These applications illustrate that as an input to process-based or empirical models in a carbon monitoring system, crop rotations can be part of an attributional framework (West et al., 2013), linking ecosystem function outcomes to originating sources (Zhang et al., 2010) at multiple scales including individual fields (Daggupati et al., 2011). Further, by determining areas where non-agricultural land-covers exist in rotation with cultivated fields, we can improve the idle/fallow cropland mapping and CRP mapping process in CDL. Also, mapping of tillage extent and intensity patterns can be greatly improved by using crop rotations to produce expert-rules that determine probability of a field being tilled (Johnson, 2013). Finally, field boundaries can be generated 
using the crop rotations product under the assumption that each field has a unique crop rotation pattern over time.

\section{Conclusions}

Modeling approaches are increasingly using crop rotation patterns instead of single crops to estimate the environmental impacts of agricultural activities. Fine resolution, spatially explicit management information can help constrain the modeling uncertainty of spatial and temporal patterns and magnitude of terrestrial carbon fluxes. However, computational and analyst resource bottlenecks constrain modeling frameworks in the number of crop rotations they can efficiently simulate. To address this problem, we present the RECRUIT algorithm which uses multi-year CDL data to identify representative crop rotations in the WCB. We find that a small number (82) of representative crop rotations can account for over $90 \%$ of the spatio-temporal variability of the more than 13,000 rotations in the WCB (Fig. 8). The area estimates of the representative crop rotations are comparable to those from agricultural census data. Using the crop rotation product, we are able to detect pronounced shifts from grassland to monoculture corn and monoculture soybean cultivation within the last few years in the ecologically sensitive PPR. Given the novel capability of RECRUIT to flexibly and efficiently derive representative crop rotation patterns in a spatially and temporally explicit manner, it is expected to be a useful tool for providing input data to drive agro-ecosystem models and for detecting shifts in cropping patterns in response to environmental and socio-economic changes. 


\section{Acknowledgements}

We gratefully acknowledge the support provided by the US DOE Great Lakes Bioenergy Research Center (DOE BER Office of Science DE-FC02-07ER64494) and US DOE Office of Science (DOE BER Office of Science DE-AC06-76RLO 1830) and NASA (NNH08ZDA001N, NNX10AO03G and NNH12AU03I). Thanks to Dr. Jonathan Resop from the University of Maryland for providing useful feedback on a draft version of the manuscript. We would like to thank two anonymous reviewers for their guidance in improving this manuscript.

\section{References}

M. Arabi, J. R. Frankenberger, B. A. Engel, J. G. Arnold

Representation of agricultural conservation practices with SWAT

Hydrol. Process., 22(16) (2008), pp. 3042-3055

F. J. J. A. Bianchi, C. J. H. Booij, T. Tscharntke

Sustainable pest regulation in agricultural landscapes: a review on landscape composition, biodiversity and natural pest control

Proc. R. Soc. B., 273(1595) (2006), pp. 1715-1727

C. Boryan, Z. Yang, R. Mueller, M. Craig

Monitoring US agriculture: The US Department of Agriculture, National agricultural statistics service, cropland data layer program

Geocarto Int., 26(5) (2011), pp. 341-358 
D.G. Bullock

\section{Crop rotation}

Crit. Rev. Plant Sci., 11 (1992), pp. 309-326

M. S. Castellazzi, G. A. Wood, P. J. Burgess, J. Morris, K. F. Conrad, J. N. Perry

A systematic representation of crop rotations

Agr. Syst., 97(1) (2008), pp. 26-33

J. Change, M.C. Hansen, K. Pittman, M. Carroll, C. Dimiceli

Corn and soybean mapping in the United States using MODIS time-series data sets

Agron. J., 99 (2007), pp. 1654-1664

P. Daggupati, K. R. Douglas-Mankin, A. Y. Sheshukov, P. L. Barnes, D. L. Devlin

Field-level targeting using SWAT: Mapping output from HRUs to fields and assessing

limitations of GIS input data

Trans. ASABE, 54 (2) (2011), pp. 501-514

N. K. Detlefsen, A. L. Jensen

Modelling optimal crop sequences using network flows

Agr. Syst., 94(2) (2007), pp. 566-572

C. Dimitri, A. B. Effland, N. C. Conklin 


\section{The 20th century transformation of US agriculture and farm policy}

US Department of Agriculture, Economic Research Service, (2005), Economic information bulletin, no. 3

S. Dogliotti, W. A. H. Rossing, M. K. Van Ittersum

ROTAT, a tool for systematically generating crop rotations

Eur. J. Agron.,19(2) (2003), pp. 239-250

J. A. Foley, N. Ramankutty, K. A. Brauman, E. S. Cassidy, J. S. Gerber, M. Johnston, N. D. Mueller, C. O'Connell, D. K. Ray, P. C. West, C. Balzer, E. M. Bennett, S. R. Carpenter, J. Hill, C. Monfreda, S. Polansky, J. Rockström, J. Sheehan, S. Siebert, D. Tilman, D. P. M. Zaks Solutions for a cultivated planet

Nature, 478(7369) (2011), pp. 337-342

F. Gao, T. He, J. G. Masek, Y. Shuai, C. B. Schaaf, Z. Wang

Influence of angular effects and adjustment on medium resolution sensors for crop monitoring

2013 Second International Conference on Agro-Geoinformatics (2013), pp. 296-301

M. M. Gardiner, D. A. Landis, C. Gratton, C. D. DiFonzo, M. O'Neal, J. M. Chacon, M. T. Wayo, N. P. Schmidt, E. E. Mueller, G. E. Heimpel

Landscape diversity enhances biological control of an introduced crop pest in the northcentral USA 
Ecol. Appl., 19(1) (2009), pp. 143-154

I. Gelfand, R. Sahajpal, X. Zhang, R. C. Izaurralde, K. L. Gross, G. P. Robertson

Sustainable bioenergy production from marginal lands in the US Midwest

Nature, 493(7433), pp. 514-517

S. N. Goward, G. Chander, M. Pagnutti, A. Marx, R. Ryan, N. Thomas, R. Tetrault

Complementarity of ResourceSat-1 AWiFS and Landsat TM/ETM+ sensors

Remote Sens. Environ., 123 (2012), pp. 41-56

T. W. Hertel, A. A. Golub, A. D. Jones, M. O'Hare, R. J. Plevin, D. M. Kammen

Effects of US maize ethanol on global land use and greenhouse gas emissions: estimating market-mediated responses

BioScience, 60(3) (2010), pp. 223-231

O. B. Hesterman, M. P. Russelle, C. C. Shaeffer, G.H. Heichel

Nitrogen utilization from fertilizer and legume residues in legume-corn rotations

Agron. J., 79(4) (1987), pp. 726-731

R. C. Izaurralde, J. R. Williams, W. M. Post, A. M. Thomson, W. B. McGill, L. B., Owens, R. Lal

Long-term modeling of soil $\mathrm{C}$ erosion and sequestration at the small watershed scale Clim. Chang., 80(1-2) (2007), pp. 73-90 
M. E. Jakubauskas, D. R. Legates, J. H. Kastens

Crop identification using harmonic analysis of time-series AVHRR NDVI data

Comput. Electron. Agr., 37(1) (2002), pp. 127-139

L. K. James, S. M. Swinton, K. D. Thelen

Profitability analysis of cellulosic energy crops compared with corn

Agron. J., 102(2), pp. 675-687

D. M. Johnson

A comparison of coincident Landsat-5 TM and Resourcesat-1 AWiFS imagery for classifying croplands

Photogramm. Eng. Remote Sens., 74(11) (2008), pp. 1413-1423

W. C. Johnson, B. Werner, G. R. Guntenspergen, R. A. Voldseth, B. Millett, D. E. Naugle, M.

Tulbure, R. W. H. Carroll, J. Tracy, C. Olawsky

Prairie wetland complexes as landscape functional units in a changing climate

BioScience, 60(2), pp. 128-140

D. M. Johnson

A 2010 map estimate of annually tilled cropland within the conterminous United States Agr. Syst., 114 (2013), pp. 95-105 
C. A. Johnston

Wetland Losses Due to Row Crop Expansion in the Dakota Prairie Pothole Region

Wetlands, 33(1) (2013), pp. 175-182

R. Lal

Soil carbon sequestration impacts on global climate change and food security

Science, 304(5677) (2004), pp. 1623-1627

D. A. Landis, M. M. Gardiner, W. van der Werf, S. M. Swinton

Increasing corn for biofuel production reduces biocontrol services in agricultural landscapes

Proc. Natl. Acad. Sci., 105(51) (2008), pp. 20552-20557

A. E. Larsen

Agricultural landscape simplification does not consistently drive insecticide use

Proc. Natl. Acad. Sci., 110(38) (2013), pp. 15330-15335

M. Liebman, E. Dyck

Crop rotation and intercropping strategies for weed management

Ecol. Appl., 3(1) (1993), pp. 92-122

J. V. Mannering, D.R. Griffin

Value of crop rotations under various tillage systems 
Purdue Univ. Coop. Ext. Serv. Pub. (Tillage) (1981) AY-230

B. A. McCarl, U. A. Schneider

The cost of greenhouse gas mitigation in US agriculture and forestry

Science, 294(21) (2008), pp. 2481-2482

T. D. Meehan, C. Gratton, E. Diehl, N. D. Hunt, D. F. Mooney, S. J. Ventura, B. L. Barham, R.

D. Jackson

Ecosystem-Service Tradeoffs Associated with Switching from Annual to Perennial Energy

Crops in Riparian Zones of the US Midwest

PLoS ONE 8(11) (2013), e80093

T. D. Meehan, A. H. Hurlbert, C. Gratton

Bird communities in future bioenergy landscapes of the Upper Midwest

Proc. Natl. Acad. Sci, 107(43) (2010), pp. 18533-18538

T. D. Meehan, B. P. Werling, D. A. Landis, C. Gratton

Agricultural landscape simplification and insecticide use in the Midwestern United States

Proc. Natl. Acad. Sci., 108(28) (2011), pp. 11500-11505

M. Mehaffey, R. Van Remortel, E. Smith, R. Bruins

Developing a dataset to assess ecosystem services in the Midwest United States

Int. J. Geogr. Inf. Sci., 25(4) (2011), pp. 681-695 
D. J. Muth Jr, K. M. Bryden, R. G. Nelson

Sustainable agricultural residue removal for bioenergy: A spatially comprehensive US national assessment

Appl. Energ., 102 (2013), pp. 403-417

F.J. Pierce, C.W. Rice

Crop rotation and its impact on efficiency of water and nitrogen use

Cropping Strategies for Efficient Use of Water and Nitrogen, ASA Special Publication 51ASA/CSSA/SSSA, Madison (1988), pp. 21-42

J. D. Plourde, C. P. Bryan, K. P. Burak

Evidence for increased monoculture cropping in the Central United States

Agriculture, Ecosystems \& Environment 165(15), 50-59

C. Potter, S. Klooster, S. Hiatt, M. Fladeland, V. Genovese, P. Gross

Methane emissions from natural wetlands in the United States: Satellite-derived estimation based on ecosystem carbon cycling

Earth Interact., 10(22) (2006), pp. 1-12

N. Ramankutty, A. T. Evan, C. Monfreda, J. A. Foley

Farming the planet: 1. Geographic distribution of global agricultural lands in the year 2000 
Global Biogeochem. Cycles, 22(1) (2008), GB1003

E. S. Ristad, P. N. Yianilos

Learning string-edit distance

IEEE Transactions on Pattern Analysis and Machine Intelligence, 20(5) (1998), pp. 522-532

G. P. Robertson, E. A. Paul, R. R. Harwood

Greenhouse gases in intensive agriculture: contributions of individual gases to the radiative

forcing of the atmosphere

Science, 289(5486) (2000), pp. 1922-1925

S. Secchi, L. Kurkalova, P. W. Gassman, C. Hart

Land use change in a biofuels hotspot: The case of Iowa, USA

Biomass Bioenergy, 35(6) (2011), pp. 2391-2400

R. Srinivasan, X. Zhang, J. Arnold

SWAT ungauged: hydrological budget and crop yield predictions in the Upper Mississippi

\section{River Basin}

Trans. ASABE, 53(5) (2010), pp. 1533-1546

A. J. Stern, P. C. Doraiswamy, E. R. Hunt

Changes of crop rotation in Iowa determined from the United States Department of Agriculture, National Agricultural Statistics Service cropland data layer product 
Journal of Applied Remote Sensing, 6(1) (2012), 063590-063590

D. Tilman, K. G. Cassman, P. A. Matson, R. Naylor, S. Polansky

Agricultural sustainability and intensive production practices

Nature, 418(6898) (2002), pp. 671-677

J. R. G. Townshend, C. Huang, S. N. V. Kalluri, R. S. Defries, S. Liang, K. Yang

Beware of per-pixel characterization of land cover

Int. J. Remote Sens., 21(4) (2000), pp. 839-843

R. E. Turner, N. N. Rabalais

Linking landscape and water quality in the Mississippi River Basin for 200 years

BioScience, 53(6) (2003), pp. 563-572

U.S. Department of Agriculture (2000). Summary Report: 1997 National Resources Inventory (revised December 2000). Natural Resources Conservation Service, Washington, DC, and Statistical Laboratory, Iowa State University, Ames, Iowa

U.S. Department of Agriculture (2008). Crop Production 2007 Summary. National Agricultural Statistics Service, Washington DC. 
U.S. Department of Agriculture, National Agricultural Statistics Service, (2009). 2007 Census of Agriculture, United States Summary and State Data, volume 1, Geographic Area Series, Part 51, AC-07-A-51.

U.S. Department of Agriculture, (2011a). Crop Production 2010 Summary. National Agricultural Statistics Service, Washington DC.

U.S. Department of Agriculture, National Agricultural Statistics Service, (2011b). Acreage. http://usda.mannlib.cornell.edu/MannUsda/viewDocumentInfo.do?documentID=1000 B. D. Wardlow, S. L. Egbert

Large-area crop mapping using time-series MODIS 250 m NDVI data: An assessment for the US Central Great Plains

Remote Sens. Environ., 112(3), pp. 1096-1116

W. Han, Z. Yang, L. Di, R. Mueller

CropScape: A Web service based application for exploring and disseminating US conterminous geospatial cropland data products for decision support

Comput. Electron. Agr., 84 (2012): pp. 111-123

T. O. West, M. E. Brown, R. M. Duren, S. M. Ogle, R. H. Moss

Definition, capabilities and components of a terrestrial carbon monitoring system

Carbon Management, 4(4) (2013), pp. 413-422 
T. O. West, W. M. Post

Soil organic carbon sequestration rates by tillage and crop rotation

Soil Sci. Soc. Am. J., 66(6) (2002), pp. 1930-1946

P. C. Westcott

Ethanol Expansion in the United States: How Will the Agricultural Sector Adjust?

Economic Research Service - United States Department of Agriculture, Washington DC, USA. http://www.ers.usda.gov/Publications/FDS/2007/05May/FDS07D01/.

C. K. Wright, M. C. Wimberly

Recent land use change in the Western Corn Belt threatens grasslands and wetlands Proc. Natl. Acad. Sci., 110(10) (2013), pp. 4134-4139

G. Xian, C. Homer, J. Fry

Updating the 2001 National Land Cover Database land cover classification to 2006 by using Landsat imagery change detection methods

Remote Sens. Environ., 113(6) (2009), pp. 1133-1147

Y. Xiao, C. Mignolet, J. F. Mari, M. Benoît

Modeling the spatial distribution of crop sequences at a large regional scale using landcover survey data: A case from France

Comput. Electron. Agr., 102 (2014), pp. 51-63 
X. Zhang, R. C. Izaurralde, D. Manowitz, T. O. West, W. M. Post, A. M. Thomson, V. P. Bandaru, J. Nichols, J. R. Williams

An integrative modeling framework to evaluate the productivity and sustainability of biofuel crop production systems

GCB Bioenergy, 2(5) (2010), pp. 258-277

X. Zhang, R. Sahajpal, D. H. Manowitz, K. Zhao, S. Leduc, M. Xu, W. Xiong, A. Zhang, R. C. Izaurralde, A. M. Thomson, T. O. West, M. W. Post

High Resolution Agroecosystem Modeling: A Case Study on the Sensitivity of Cropland Carbon Flux Simulations to Soils Data Resolution

Sci. Total Environ., 479 (2014), pp. 138-150

${ }^{1}$ http://www.nass.usda.gov/research/Cropland/sarsfaqs2.html\#Section4_7.0 